Article

\title{
The Global Legal Entity Identifier System: How Can It Deliver? ${ }^{1}$
}

Ka Kei Chan ${ }^{2}$ and Alistair Milne ${ }^{3}$

\begin{abstract}
We examine the global legal entity identifier (LEI) system for the identification of participants in financial markets. Semi-structured interviews with data professionals reveal the many ways in which the LEI can improve both business process efficiency and counterparty and credit risk management. Larger social benefits, including monitoring of systemic financial risk, are achievable if it becomes the accepted universal standard for legal entity identification. Our interviews also review the substantial co-ordination and investment barriers to LEI adoption. To address these, a clear regulatory-led road map is needed for its future development with widespread application in regulatory reporting.
\end{abstract}

\section{JEL numbers: G20, G28, M15}

Keywords: Big data; Data Standards; Entity Identifiers; Macroprudential Policy; Regulation; Risk Management; Dodd-Frank Act; Operational Efficiency; Systemic Risk

\section{Introduction}

Fragmented financial data has been a serious problem in financial sector for decades. This fragmented data creates problems to private sector participants, including both operational problems (such as inefficient management of client records) and inadequate management information on risk and on costs. It also makes firms opaque to regulators, hindering the effectiveness of monitoring and responding to systemic risk, and in resolving financial failures through reorganizing of credit claims. Aware of these problems and their contribution to the global financial crisis of 2007-2008, the world's regulatory authorities have sought to address them by mandating the global legal entity identifier (LEI) system for use in financial markets

This paper has three goals: first to describe the LEI system; second to assess the benefits of the global LEI in terms of both reduced operational and credit risks, lower costs and improved regulatory oversight; third to discuss how best to address the technical, business, economic and regulatory barriers that must be overcome if it is to succeed as a global universal standard.

To address these goals we must examine in detail both the application of entity identifiers in global capital market operations and understand the institutional barriers (organizational, regulatory, legal etc.) to the development and adoption of the global LEI system. The analysis in this paper is therefore conceptual and qualitative, not quantitative; it is though still empirical, using data

\footnotetext{
1 This paper is an updated version of (Chan \& Milne, 2013) written with the support of a grant 2012-5-50CD from the Alfred P. Sloan Foundation, updated to take account of developments in the intervening five years. The opinions expressed here are our own, not those of any of the institutions involved in creating the LEI or the many individuals who have generously given of their time in order to be interviewed on the development and future of the system.

2 Brunel University London, UK

3 Corresponding author: School of Business and Economics, Loughborough University, UK, a.k.l.milne@lboro.ac.uk
} 
obtained from the established qualitative research tool of semi-structured interviews (for discussion of these tools see e.g. Jenner et al. 2004; Harrell and Bradley 2009). ${ }^{4}$

In a semi-structured interview a set of questions is used as the basis for a transcribed conversation. The resulting data is then used for analyzing the research questions from the range of perspectives offered by those interviewed. This is a standard technique for answering research questions requiring consideration of the views of a range of stakeholders or participants.

The primary interview data in this research was collected from twelve semi-structured interviews via telephone or Skype. The sample selection of our interviewees was based on a list of contacts through the Private Sector Preparatory Group (or PSPG, this is described in Section 2). Our interviewees were five senior data managers in the major global investment banks and seven industry experts working for advisory firms or consultancies actively involved in the discussion of GLEIS adoption. The questions for the interview were submitted to the interviewees in advance to allow them to provide more detailed and structured answers. At the first stage of research each interview was then transcribed from audio recording or detailed notes (this data remains confidential). At the second stage of the research a summary of interviews was then prepared, with key points for each interview question highlighting similarities and differences in the opinions of the interviewees. The appendix of this paper provides both a list of the questions we asked during the interviews and the second stage summary of the answers provided by the interviewees.

What emerges from this investigation? The LEI project has been ongoing for more than six years. We find that while the potential benefits are large the success of the global LEI is still not assured. There is a danger of it becoming yet another identifier used in some contexts but not in others. If the global LEI system is to deliver then it needs to become the unquestioned choice of entity identifier across the full range of wholesale and corporate financial services. This requires a clear vision of its development from regulators and senior management, promoting its use as the sole identifier of counterparties and clients in business processes and regulatory reporting.

The paper is organized as follows. ${ }^{5}$ Section 2, drawing on public domain sources, describes how the idea of having a standard universal identifier for wholesale market participants first attracted political support as part of the US Dodd-Frank Act and was then later was taken up as an international initiative under the auspices of the Financial Stability Board. It also outlines the structure and operation of the system and the steps taken in implementation up until the fall of 2018.

The following two sections draw on the semi-structured interviews, conducted in 2013 with data professionals. Section 3 examines the two broad categories of benefits anticipated from global LEI system, cost efficiency and improved risk management. Section 4 considers the role of the global LEI in keeping track of corporate hierarchies, for better assessment of counterparty risk, for the mapping of the network structure of the financial system and for the effective resolution of firms in financial distress.

Section 5 reviews the rather limited available quantitative evidence on the magnitude of cost savings achievable from the LEI and other forms of standardization in financial services. It also offers a brief discussion of the barriers to adoption of the global LEI system and presents our case for establishing a 'road map' for future development of the system. Section 6 returns to our interview evidence and discusses the barriers to adoption. Section 7 concludes. An Appendix lists our interview questions and summarizes our interviewer responses.

\footnotetext{
${ }^{4}$ We are unable to offer a detailed quantitative analysis because to date the LEI has been mainly used in a relatively narrow context, that of reporting to derivative trade repositories; only when applied to address a much wider range of problems of entity identification in global financial markets will full quantitative analysis of the benefits of the GLEI be possible.

${ }^{5}$ We do not offer a separate literature review. This is because there is not a great deal of literature on the global LEI system, whether in peer-reviewed journal articles, working papers or policy and consultancy reports. We refer to other research where it relates closely to our own, mostly in footnotes. The paper closest to our own is (Grody, 2018) who endorses the value to be had from the global LEI but emphasises the challenge of data governance and maintaining data standards.
} 


\section{The development of the global LEI system}

This section summarizes the development of the global LEI system. It is one of the principal global regulatory initiatives introduced in the ten years since the global financial crisis of 2007-2008. It is being undertaken in order to provide both private sector institutions and regulators with unique and unambiguous identification of all financial market participants. By the end of 2017, there were over 1 million LEIs issued to legal entities, issuers of securities with a total value of EUR 95 trillion worldwide (ROC, 2018).

\subsection{The creation of the global LEI system}

The initiative originated with the Dodd-Frank Act (the Wall Street Reform and Consumer Protection Act) signed into federal law on 21 ${ }^{\text {st }}$ July 2010. A main objective of this act (Title 1 of the 16 titles) was to enhance financial stability by better identifying, evaluating and managing risks of both financial and non-financial organizations.

Two new bodies were created to perform this task. The Financial Stability Oversight Council (FSOC) was set up to provide "collective accountability [amongst state and Federal regulators] for identifying risks and responding to emerging threats to financial stability" ${ }^{6}$ The Office of Financial Research (OFR) was established as a department of the US Treasury to improve the quality of financial data available to policymakers and facilitating more robust and sophisticated analysis of the financial system. ${ }^{7}$

Standardized legal entity identification, especially of counterparties in OTC derivative markets, was identified as a key gap in regulatory data. The Office of Financial Research, through Lewis Alexander, General Counsellor to US Treasury Secretary Geithner, launched the initiative with a policy statement about the establishment of a standard legal identifiers (see (Alexander, 2010)). ${ }^{8}$ However, it soon became apparent that if such a system was to be effective it had to be global not national. Therefore, since 2011, the effort for establishing the global LEI system has been taken forward by the Basel based Financial Stability Board (FSB), working with regulators from all the major financial jurisdictions.

The G20 established the FSB to carry out global co-ordination of financial regulation of this kind (Draghi, 2009; FSB, 2009). The global LEI system is far from the only task being addressed by the FSB. Others include the use of 'macroprudential' policy tools to mitigate excessive financial risk; the central clearing and reporting of OTC derivatives; the resolution of cross-border and systemically important financial institutions; remuneration in financial institutions; regulation of hedge funds, credit rating agencies and securitized instruments, and oversight of shadow banking. ${ }^{9}$ But the global LEI system can be seen as fundamental: without accurate identification it will be much harder to achieve other FSB objectives.

The global LEI system was publicly announced by the FSB 8 th June 2012 (FSB, 2012a). This report sets out high level principles and 35 recommendations for the implementation of the global LEI system. The report was endorsed by the G20 at the Los Cabos Summit of 18-19 th June 2012, who then asked FSB to take forward the work to implement the system. This led to the establishment of the temporary LEI Implementation Group (IG) consisting of representatives the global regulatory community. The IG and its permanent successor the Legal Entity Identifier Regulatory Oversight Committee (LEI ROC) have been responsible for guiding the implementation and operation of the global LEI system.

\footnotetext{
${ }^{6}$ Source: http://www.treasury.gov/initiatives/fsoc/about/Pages/default.aspx

7 Source: http://www.treasury.gov/initiatives/ofr/about/Pages/default.aspx

8 (FSOC, 2012), page 140, describes this role as follows 'The Office of Financial Research (OFR), established in Title I of the Dodd-Frank Act, is tasked with improving the quality of financial data and data analytics along multiple dimensions, including LEI implementation and enhancement.'

9 Progress reports on the various FSB initiatives are available from
} http://www.financialstabilityboard.org/list/fsb_publications/tid_178/index.htm 
Figure 1 illustrates the four-tier federated structure of the global LEI system. The top tier is the 'constitution' of the LEI, comprising agreed high level principles and together with a Charter governing the activities of the Regulatory Oversight Committee Charter. Below this in the second tier is the Regulatory Oversight Committee (ROC), representing regulators from jurisdictions around the world and responsible for the development and oversight of the system. They work together with a technical committee on evaluation and standards (CES). The third tier, which will be responsible for the operation of the system, consists of the Global LEI Foundation (GLEIF) together with a Central Operating Unit (COU). Finally in the bottom tier are the various Local Operating Units (LOUs) issuing LEIs to customers in individual jurisdictions.

Figure 1. Federated Global LEI Structure.

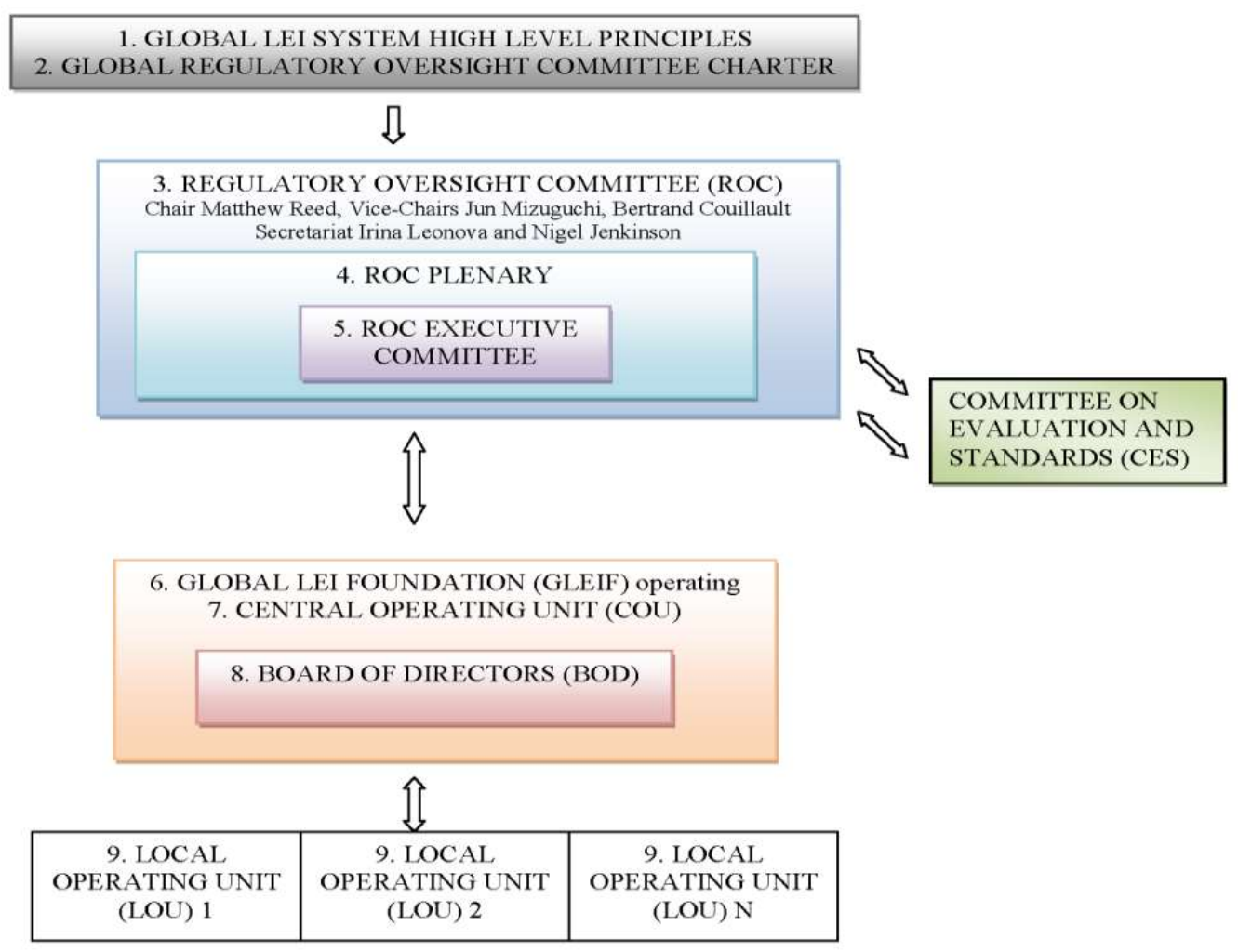

Source: LEI ROC (http://wwww.leiroc.org/publications/leistructurediagram.pdf)

To support the IG in its preparatory work to establish the global LEI system, the FSB put out a call on $3^{\text {rd }}$ July 2012 for interested parties from the private sector, including data and technology providers, academics, and other parties to participate in the LEI Private Sector Preparatory Group (PSPG). Representatives from well over 100 institutions from some 25 countries have joined the PSPG (FSB, 2012c). The inaugural meeting was held in New York City, USA on 25 th July 2012 and active discussion on the design and operation of the global LEI system has continued since then.

Progress with the creation of the global LEI system is documented by a series of progress notes, the first five released by the FSB (FSB, 2012d, 2013) with subsequent notes released by the ROC on its own website (in March 2013 (LEI ROC, 2013), June 2013 (LEI ROC, 2013), November 2015 (LEI ROC, 2015) and May 2018 (LEI ROC, 2018)). The charter setting out the mission and responsibilities of the ROC was approved by the November 2012 meeting of the G20 (FSB, 2012b). The ROC itself 
was then created on $11^{\text {th }}$ Jan 2013 taking over responsibility for the governance and oversight of the global LEI system in the broad public interest. ${ }^{10}$

The ROC has now 72 member authorities and 19 observers including representatives of national and regional bodies covering 65 jurisdictions (LEI ROC, 2018). After the establishment of the Global LEI Foundation (GLEIF) in June 2014, a clearly distinct division of responsibilities between ROC and GLEIF was established. ROC is responsible for policy standards, including the definition of eligibility to obtain an LEI, the definition of reference data, the frequency of update for reference data, due diligence and any other standard necessary to ensure sufficient data quality, and the principles governing data and the information access. The GLEIF is responsible of developing the operational and technical standards for GLEIS, such as data file formats and the normalization of reference data, and provides operational manuals, methods and procedures for the GLEIF or for LOUs.

From 7 October 2015, an institution that wants to become a LOU need to be accredited by GLEIF. All the pre-LOUs, which were endorsed by the ROC in the start-up period, were required to undergo accreditation with GLEIF by January 2018. So far, 32 LOUs are accredited by GLEIF for the issuance of LEIs. ${ }^{11}$

\subsection{Key issues in the design of the global LEI system}

A contentious but now resolved issue has been the numbering structure for the LEI. As with many other global standards, the LEI has been approved as ISO standard, number $17742 .{ }^{12}$ This however is a fairly general statement, requiring only a 20 digit alphanumeric number with no embedded intelligence (i.e. the number itself must not contain information about legal entities except the prefix of LOU to which the entities belong). All such entity specific information will be recorded in separate reference fields.

The IG commissioned an engineering study written by a number of PSPG participants (Braswell et al., 2012) to examine if the LEI should be entirely unstructured or whether there should be some partitioning of the 20 digits. This study concluded that a partitioning was essential in order to allow fully decentralized allocation. The IG accepted this recommendation and determined that the first four digits of LEI should be used to allocate blocks of LEI numbers to individual LOUs, with the fifth and sixth digits set at zero (effectively reserving them in case of any unforeseen need for further partitioning). The next 12-digit component is the entity specific part. The last two digits are the check code according to the ISO 17442 standard.

The current required reference data set includes "Level 1 business card" information on entities (e.g. official name of the legal entity, address of its headquarters) and the developing "Level 2 relationships among entities" information. The Level 2 data currently focuses on the additional reference data on the direct accounting consolidating parent and the ultimate accounting consolidating parent(s) of the legal entities and the relationship/ownership data. By the end of 2017, 41,656 direct parents and 46,372 ultimate parents had been identified. 443,211 $(444,301)$ entities had reported to have no direct (ultimate) parents. 18,000 entities were not able to provide this information due to legal obstacles or detrimental effects to the legal entity or the relevant parent (LEI ROC, 2018).

This rest of this section describes the range of potential benefits from introduction of the global LEI system. We first offer some discussion of the deep-seated identification problems in the industry. We then summarize the views on the potential benefits of LEI, as revealed by our interviews with data professionals. These benefits can be divided into two broad groups. The first are efficiency gains in the wide range of processes undertaken by financial institutions dealing with corporate and wholesale customers. The second are better measurement, monitoring and response

\footnotetext{
10 A list of members and observers can be found at www.leiroc.org/about/membersandobservers/index.htm

11 The list of LOUs is available via https://www.gleif.org/en/about-lei/get-an-lei-find-lei-issuing-organizations.

12 The standard itself can be purchased via http://www.iso.org/iso/catalogue detail?csnumber=59771. See http://www.iso.org/iso/home/news_index/news_archive/news.htm?refid=Ref1449 for description.
} 
to risk exposure, especially to counterparties in financial markets, both by market participants and regulators.

\subsection{The identification problem}

The root problem addressed by the global LEI is the absence of any standardized corporate entity identifiers in financial markets around the world. Standard identification is needed because relying on names alone, with manual entry or human identification, results in widespread duplication of work and other processing inefficiencies.

There are many examples of such errors. These include: (i) similar names for many different entities within the same organization; ${ }^{13}$ (ii) different spellings and spelling mistakes; ${ }^{14}$ (iii) duplicate client profiles when 'onboarding' has been conducted separately by different units; e.g. in different jurisdictions within the same firm; (iv) errors in manual data processing; e.g. from mistranslations. ${ }^{15}$ All of these problems can be addressed by having a standard and unique legal entity identifier.

A particular issue, that poses particular problems in credit and counterparty risk-management, is understanding corporate hierarchies, obtaining information on the relationship amongst subsidiaries and their parent. (Carmassi \& Herring, 2016) provide evidence on the complexity of corporate hierarchies, showing a strong correlation with previous merger and acquisition activities. This complexity problem is especially difficult in but not limited to large systemically important financial institutions.

One consequence of these errors is difficulties in managing financial failure. Our interviews (reported in Sections 3 and 4) highlight the identity inconsistencies following the failure of Lehman Brothers in 2008; one of our interviewees discussed similar naming problems with Long Term Capital Management, following its failure in 1998; other sources refer to similar problems following the 1990 failure of Drexell Burnham Lambert, the 1995 failure of Barings Bank, the 2001 failure of Enron in 2001 and the 2011 failure of MF Global. ${ }^{16}$ In all these failures counterparties found it extremely difficult to quickly identify and quantify the scale of their exposures, because of the multiplicity of different naming conventions in their different internal systems and the difficulty of maintaining a complete view of the hierarchies of these failed counterparties.

Agreement on an identifier does not solve all data issues in risk and business management, the relationship with the counterparty (adviser, principal, broker etc.) must be accurately captured; and information on financial obligations kept up to date. Standardized legal entity identification is though a foundation for effective further data management.

As an illustration of the scale of this problem, we can cite figures provided by one major vendor with whom we discussed entity identification. They told us that the proportion of duplicate clients that trade with the sell-side firms in the global capital markets ranges from $65-85 \%$, depending on asset class.

There have been several efforts by the industry to establish standardized industry wide identifiers, both for instruments and for firms (Grody, Harmantzis, and Kaple 2007 recount some of this history). As early as 1968 the US industry established the Banking and Securities Industry Committee (BASIC) which supported identification standards for use in computer processing, both the CUSIP number (Committee on Uniform Securities Identification Procedure) and the less widely used FINS (Financial Institution Numbering System). But - despite renewed efforts during the subsequent forty years - the industry never succeeded in establishing a single standard for entity identification.

13 (Powell, 2011) refers to the surprisingly large number of US banks with identical names: no less than 14 legally separated US banks all called City National Bank.

14 (FSB, 2012a) refers to the wide number of different naming conventions for many institutions.

${ }_{15}$ One of our interviewees referred to the example of Stichting in Dutch, Stiftung in German, the term that could be translated as the equivalent of a UK 'charitable trust'. It remains a common mistake in manual data processing to assume that Stichting is the name of a company.

16 (A-Team_Group, 2009) provide an insightful discussion in relation to the crisis of 2008. 
Some progress was made with the international agreement on ISIN numbers, created by combining a country code with a local national security identifier (such as CUSIP in the US or SEDOL in the UK). But, while used in international security transactions, ISINs does not provide a solution for standard global legal entity identification.

Many other identifier solutions are available, including BIC and SWIFT numbers for international bank payments (but these are branch not legal entity identifiers); Dun and Bradstreet numbers; and the company registration numbers in individual jurisdictions. ${ }^{17}$ But none of these can be used in a consistent fashion across business operations, because they do not provide universal coverage of market participants, because they often fail to identify legal entities and because of shortcomings in data quality.

The development of these identifiers, for particular countries, industry sectors, and market activities prevents their wider use outside the purpose of their creation. A practical solution is to create a new identifier, which is accepted generally by all countries, by all industry sectors, and for the use in a wide range of market activities. The creation of the federated Global LEI structure and LEI, so far, are appropriate to overcome some identification problems: the language translation can be effectively handled by LOUs (local operating units); duplicate client profiles can be removed once identifies from the supplied LEI; the problems of assessing counterparty exposures can also be improved as long as LEI is widely used for recording market activities such as financial transactions.

Identification problems are not limited to business entities; they also occur in the identification of products and transactions. New identifiers are now being proposed by FSB (FSB, 2017, 2018). Their design and application will be closely linked to LEI to create a comprehensive solution to different forms of identification problems in markets.

\subsection{Reporting immediate and ultimate parents}

One intended application of the LEI - discussed in detail below in Section 4 - is underpinning a full understanding of corporate hierarchies. In practice, as outline by the LEI ROC, the facility to investigate corporate hierarchies has only been recently introduced into the LEI data fields. By 2017 LEI applications were required to report, where these could be identified according to accounting consolidation rules, both their immediate parent (corporate owner) and ultimate parent (holding company at group level). In practice not much more than ten percent of LEIs report their immediate and ultimate parents. ${ }^{18}$

\footnotetext{
${ }^{17}$ This is a far from complete list. (Bottega \& Powell, 2011) mention several more: 'A number of vendors and industry utilities issue entity identification numbers today, including but not limited to Standard \& Poor's, Avox, Omgeo, FactSet, Bloomberg, Thomson Reuters, Dun \& Bradstreet, Telekurs, Markit (red code), SWIFT, and Alacra.'

18 See (LEI ROC, 2018) who report that “As of 31 December 2017, 41,656 direct parents and 46,372 ultimate parents had been identified with an LEI in the GLEIS. In addition, 443,211 entities had reported that there are no parents meeting the GLEIS definition: for example (i) the entity is controlled by natural person(s) without any intermediate legal entity meeting the definition of parent in the GLEIS; (ii) the entity is controlled by legal entities not subject to preparing consolidated financial statements (given the definition of parents in the GLEIS, e.g., a number of investment funds) (iii) there is no known person controlling the entity (e.g., diversified shareholding). Similarly, 444,301 reported the absence of an ultimate parent. For both types of parent relationships, some 18,000 entities declared that legal obstacles prevented them from providing or publishing this information or the disclosure of this information would be detrimental to the legal entity or the relevant parent." The ROC continues with a pilot on hierarchy reporting and is also examining extensions to include the reporting of large international branches. There is though clearly some way to go before the LEI system adequately handles complications such as these.
} 


\section{Efficiency gains}

Our interviews revealed many potential efficiency gains for firms from ending this pervasive fragmentation of entity identification. ${ }^{19}$ We group these in four sub-categories:

\subsection{Improved client data management}

1. Client on-boarding. The process of 'client on-boarding' absorbs a substantial amount of resources. Creating a new client account requires establishing and validating a range of information, and this process is often repeated unnecessarily, in different jurisdictions and across different business lines (trading desks, whether fixed-income, equities, foreign exchange or derivatives; credit and cash management relationships with large corporates; prime brokerage for hedge funds), often starting again from scratch.

2. Updating of client information. Compliance with 'know your customer' (KYC) regulations requires not just initial on-boarding but also updating of information on clients. Internal information systems need to take account of corporate actions such as takeovers and this is still a largely manual process. The major firms can have 1,000 or more staff working full time on KYC processing. Standardized identification can help automate these processes.

3. Observation of anti-money laundering (AML) regulations. This requires going through a regular 'check-list' and a large part of this effort remains manual rather than automated and is often repeated more than once in different parts of the same firm. Standardized identification can help automate these processes.

4. Better client relationship management. There has been a lot of discussion - in both financial and non-financial industries - about the using customer relationship management (CRM) systems to provide better customer service and more effective marketing. In financial services the practical implementation of CRM is hampered by inaccuracies and inconsistencies in client identification. While this is a bigger problem in retail financial services, accurate and reliable client identification can help improve customer relationship management for all types of customer.

\subsection{Straight through processing}

5. Reducing failures in post-trade order matching, clearing and settlement. These trade failures occur in both securities and derivative markets, typically because of inconsistencies in the data recorded on the two sides of the trade. The most common data inconsistency is about the identity of the counterparty (Grody, Harmantzis, and Kaple 2007) and this can be helped by using standardized legal entity identification; i.e. a unique and universal identifier which is machine readable and removes all ambiguity in automated processing when referring to a trading or financial counterparty. The LEI can serve this purpose.

\subsection{Tax, management and regulatory reporting}

6. Compliance with tax reporting requirements such as the US FATCA which requires "foreign financial institutions (FFIs) to report to the IRS information about financial accounts held by U.S. taxpayers, or by foreign entities in which U.S. taxpayers hold a substantial ownership interest."20 This is another situation where substantial manual processing costs arise because of lack of standardized identifiers. For this purpose the US authorities have introduced their own

\footnotetext{
19 The FSB announcement of the global LEI system (FSB, 2012a) pages 26-27 classifies these under only two headings ("operational efficiency" and "enhanced regulatory reporting") compared to our four.

${ }^{20}$ http://www.treasury.gov/resource-center/tax-policy/treaties/Pages/FATCA.aspx
} 
global financial intermediaries identification system (GIIN) which is totally separate from the global LEI.21

7. Complying with new regulatory reporting requirements. Regulators are after the crisis imposing much more demanding requirements for detailed information on credit and market exposures, for example those arising from Dodd-Frank, the European Market Infrastructure Regulation (EMIR) and other regulations. This is challenging in large part because most firms still have data recorded in a number of different internal systems, each with its own identifier (one interview with a global institution revealed that one firm has "six or seven different systems" just for the recording of interest rate swaps.) Even within a single system it is typically not straightforward to provide all that is required by regulators, especially with regard to detailed breakdown of counterparty exposures. We believe that similar benefits, facilitating the aggregation of positions, should arise in internal management reporting; but this was not specifically mentioned in any of our interviews.

8. Monitoring and complying with large exposure limits. Another situation where considerable manual intervention is required to take account of the impact of corporate actions such as takeovers or divestments on exposures to specific counterparties.

\subsection{Buyside services}

9. Allocation of cash and securities from block or automated trades to individual client accounts. For buy side firms a single trade is often conducted in several pieces, and must then be reassembled with the proceeds allocated between several cash or security accounts. Here again automatic processing can fail because of discrepancies in client identifiers, resulting in manual interventions which could be reduced by reliable standardized identifiers.

10. Complying with ethical and other investment mandates. Another issue for buy side firms is that funds are sometimes limited to particular types of assets, for example 'ethical' or 'green' funds that are not supposed to invest in particular types of assets. Monitoring compliance with these mandates is challenging, especially when corporate actions such as takeovers lead to a change in the business profile of security issuers.

11. Identification of investors for security underwriting. One interview mentioned a need for manual interventions to ensure that underwritten securities are credited correctly to identified client accounts.

12. Maintaining separation of client accounts. A major problem revealed by the failure of Lehman Brothers was the failure to comply with regulations (such as the CASS regulations in London) requiring separation of client and proprietary assets. Accurate client entity identification is a prerequisite for both obeying such requirements and for imposing an appropriate compliance and audit trail to ensure that this is done.

We have not interviewed anyone from the custodian industry on the potential benefits of the global LEI system. Given evidence on further reference data problems amongst custodian banks (discussed below), we believe that further benefits for buy side clients could be found also in the execution of corporate actions.

This list reveals the very wide range of situations where standardized legal identification can yield efficiency gains. The underlying problem is data fragmentation, leading to unnecessary duplication of data input and validation and frequent manual reconciliations, in what should be routine activities across the global financial services industry. A standardized global legal entity identifier used across the full range of business activities can be a foundation for removing this duplication and automating routine processes.

${ }^{21}$ See http://www.irs.gov/irm/part3/irm 03-021-112.html\#d0e850 for description of the GIIN. GIIN allows for the possibility of branch identification not legal entity identification. Section 5 below discusses this problem of competing systems of identification numbers and how it might be resolved. 


\section{Corporate hierarchies}

A key benefit of the LEI for regulators is better understanding and monitoring credit and counterparty risk measurement across firms. Today, there is incompatibility in identification between the many different systems for credit and counterparty measurement used in different firms. Regulators want individual firms to record their credit and counterparty exposures in a standardized way, so that they can collect and summarize these exposures for the entire financial system; ${ }^{22}$ they want to be able to shift the focus of regulatory data collection away from standardized regulatory reporting and towards 'contingent' reporting of exposures in response to specific supervisory concerns; ${ }^{23}$ and they want to facilitate sharing of information between regulators in different jurisdictions. ${ }^{24}$

This is the main reason for the strong political backing for the creation of the global LEI system. ${ }^{25}$ Politicians and regulators are not directly concerned with operational efficiency gains in the private sector; but they are very much interested in seeing improvements in risk-management and in better monitoring of risk by the regulatory authorities and better understanding of corporate hierarchies and resulting counterparty risks, both by firms and by regulators, are seen as key. This is widely seen as essential to improving the safety of the financial system and preventing a repeat of the global financial crisis. ${ }^{26}$

\subsection{Background: the challenge of understanding corporate hierarchies}

A major challenge here is the complexity of corporate hierarchies. Large international companies can have remarkably complex structures, often containing thousands of legal entities within the same corporate group. ${ }^{27}$ The largest global financial firms are especially complicated; for example Goldman Sachs has more than ten thousand component legal entities with a very complicated web of ownership relationships amongst them..$^{28}$ This is not unusual, such complex hierarchical structure is found in all large global firms, with financial firms being the most complicated of all.

To add to the challenge of understanding corporate hierarchies, they rarely if ever have a simple "tree structure", with a single parent entity and with each and every subsidiary wholly owned and controlled by an entity one level up in a clean layered structure. Instead actual corporate hierarchies are much more complicated and difficult to understand than this:

\footnotetext{
22 Some recent contributions to the literature (Alexander, Das, Ives, Jagadish, \& Monteleoni, 2017; Fan \& Flood, 2018; Flood, Jagadish, \& Raschid, 2016; Piechocki, 2017) explore the 'big data challenge' in financial stability monitoring, highlighting the role of standard identifies such as the LEI for effective financial stability analysis, but also stressing the limitations of the LEI in supporting the analysis of corporate hierarchies and hence systemic risk.

23 See (Bailey, King, \& Tucker, 2011)

24 This last point is emphasised by (FSB, 2012a).

${ }_{25}$ Restated for example in (Buch, 2017) who summarises the ongoing 'data gaps initiative' that seeks to promote better global data on real estate exposures, shadow banking and granular market data (including the LEI) to support better macroprudential modelling and monitoring.

26 (FSB, 2012a) page 26 describes these benefits as follows 'The LEI provides a powerful foundational tool to enhance the monitoring and management of systemic risks. Among the potential benefits are: Improved data aggregation and analysis ... Enhanced prudential supervision ... Support for orderly resolution ... Protection against market abuse.' The FSB notes in particular the scope for better supervision of firms active in multiple jurisdictions.

27 Mappings of several corporate structures including Barclays, Pearson's, Goldman Sachs, Gap and Starbucks are available on the website www.opencorporates.com. OpenCorporates announced the initial phase of this work, financed like our paper by the Alfred P. Sloan Foundation, here: http://blog.opencorporates.com/2013/07/11/open-corporate-network-data-not-just-good-but-better/

28 Source (together with accompanying illustration) from the www.opencorporates.com mapping tool.
} 
- $\quad$ There are a very wide range of patterns of share ownership. Instead of every subsidiary being wholly owned by a single parent, ownership of a subsidiary is often shared between several entities within the same corporate group, and sometimes also with outside shareholders. There can also be cross- and circular shareholdings (e.g. A holding shares in subsidiary B which in turn holds shares $\mathrm{C}$ which holds shares in $\mathrm{A}$ ). As a result it is impossible to identify a clean layered ownership hierarchy. Instead the owners of subsidiaries can be found at several degrees of separation from the top of the company or entirely outside of the company. Real-world hierarchies, far from being clean, are tangled webs of interconnections.

- Ownership of a subsidiary is not the same thing as control. In the case of corporate subsidiaries this is both because of different legal rights for different shareholders (different voting rights or reserved powers such as might be held by a 'golden share') and because relationships amongst shareholders may give effective control to a shareholder or group of shareholders even though they do not own a majority of shares.

- Many subsidiaries are established as non-corporate legal structures without shareholders, for example financial firms frequently establish trusts as investment vehicles, for example in structured- and project- finance. The trustees, with responsibility for operating the trust according to stated mandate and objectives, are appointed by the firm that establishes the trust, so they have formal control, but the degree of control is limited by the mandates and objectives of the trust. While there is no ownership of a trust, there are still 'beneficial interests' i.e. interests in the proceeds from assets and investments of the trust. Such beneficial interest may be held by legal entities within the corporate group, by outside investors or by both.

- Subsidiaries and other entities within the same group are also linked by other financial relationships, such as secured and unsecured loans, cash and security deposits, guarantees, and sometimes derivative contracts. Such financial relationships are not normally regarded as part of corporate hierarchies, but they can be critical in the context of corporate default when such internal financial arrangements are a critical determinant of the enforceability of creditor's legal claims.

- Information about the various dimensions of corporate interrelationships (ownership, control, beneficial interest, financial commitments) is not always in the public domain. In some jurisdictions ownership of public companies is disclosed in public registers; but in other jurisdictions this is not required and companies may deliberately create subsidiaries in these jurisdictions in order to make their corporate structure opaque. Information on the other dimensions of corporate interrelationships can be even harder to obtain.

For all these reasons there can be no simple, objective and clean description of corporate hierarchies. Different 'mappings' are needed to establish (i) who has ultimate control over the actions and behavior of the various subsidiaries in a group; (ii) who ultimately enjoys the benefits and bears the risks of income earned by each subsidiary; and (iii) the likely net value that might be recovered by the creditors of any particular subsidiary in the event of a default.

The consequence is that in practical application the question is one of degree: exactly how much understanding of corporate hierarchies is needed to inform business decision making? The simplest and crudest level, which suffices for many purposes, is identifying the corporate group to which a particular legal entity. Even this simplest of characterizations leaves a "grey area", for example joint-ventures, or special purpose vehicles (this is quite a common situation in project finance) that are shared between two or more corporate groups. It also ignores any differences between the operations of companies in different jurisdictions: dealing with a corporate group in jurisdiction $X$ may involve very different risk exposure than when dealing with the same corporate group in jurisdiction $\mathrm{Y}$.

\subsection{Views of our interviewees.}

In all our interviews we discussed the role that the global LEI system might play in the provision of such corporate hierarchy mappings and hence in monitoring counterparty risk. Simply having a standard legal entity identifier, supported by accurate reference data on key information 
such as jurisdiction of registration (a key piece of information which can be difficult to establish where there is no public registration of company ownership), is useful. But should the LEI system require reporting of any further information on ownership, control or beneficial interests, as part of the LEI reference data?

Our interviewees expressed a wide range of different views on this issue. Some took the view that the provision of such additional hierarchy information should not be the responsibility of the LEI system at all. Instead it should keep strictly to its core task of unique identification of legal entities, together with basic reference data such as legal name, address and jurisdiction. The responsibility for providing corporate hierarchy information should be left to third party vendors, who will be able to use the global LEI in order to provide this information as efficiently as possible to their clients.

Others argued that the LEI could usefully provide easily verified and objective hierarchy information, such as the percentage of share ownership held by other LEI registered institutions; and the name and registered address of other major shareholders. Information of this kind could help overcome gaps and inaccuracies in vendor provided corporate hierarchy information.

Even this relatively simple functionality could though be difficult to achieve. Privacy rules in some jurisdictions could prevent such information being released; and ownership information may be difficult to verify within the LEI system when the shares are held by entities which do not themselves have LEI numbers. A related issue is whether all the entities in a corporate hierarchy should be required to have an LEI number, which is desirable for fuller understanding of credit and counterparty risks but could be difficult to enforce for entities that are not themselves transacting in public financial markets.

Other PSPG participants we talked to admitted to the difficulties of reaching agreement on what corporate hierarchies should be. Still some highlighted the central importance of achieving greater transparency of corporate hierarchies as an ultimate goal of the global LEI. Amongst the points made to us were: (i) the present difficulties of obtaining complete ownership and hierarchy information, especially when some jurisdictions do not put such information into the public domain; (ii) the great benefits obtainable from having a shared 'single view' of hierarchies across the industry; (iii) the importance of effective management of systemic financial risk.

Moreover the immediate private gains to firms, in terms of an improved 'bottom line' from using the global LEI in their credit and counterparty risk management are relatively small, far less than the cost savings available from using global LEIs to remove duplicate manipulations of data and automate their operational processes. This does not imply that the credit and counterparty risk management applications of the LEI are unimportant, but it does suggest that in order to have the global LEI adopted as the universal entity identifier of choice it will be necessary to ensure that it is well suited for removing duplication and automation of business processes.

There has been lively debate, first in the PSPG and then in the ROC, on the question of what, if any, corporate hierarchy information would be required from firms. When the LEI was first launched, reporting requirements were limited to information about the entity itself. The ROC then decided (LEI ROC, 2016) that from May 2017 onward LEI registrants would be also required to report two items of accounting based corporate hierarchy information: their "ultimate accounting consolidating parent", the highest level legal entity preparing consolidated financial statements; and their "direct accounting consolidating parent" (although there are grounds which allow refusal to provide this information, for example if this is not allowed by local law or regulations or doing so would be commercially damaging). This seems sensible. Attempting to provide near-complete corporate hierarchy information as some commentators have wanted would increase costs, reduce functionality and undermine incentives for adoption. This does not rule out the possibility of developing the global LEI system further at some later stage, to provide fuller corporate hierarchy solutions. 


\subsection{Using hierarchies to improve in risk management}

Our interviews yielded a relatively short list of specific practical applications of LEI to risk management, compared to its application in business processes, and little indication that these offered substantial and immediate 'bottom line' benefit to firms themselves.

The most commonly mentioned application of legal entity identification of this kind was in dealing with counterparty failure. Still fresh in the minds of our interviewees was the complicated situation created by the collapse of Lehman Brothers over the weekend of Oct $13^{\text {th }}-14^{\text {th }} 2008$. On the Monday morning some parts of the group, in the UK and other jurisdictions, were put into court ordered administrative insolvency; other parts obtained US Chapter 11 bankruptcy protection.

Most creditors and counterparties faced great difficulties in assessing their own exposure to Lehman Brothers, which had over 7,000 component legal entities in more than 40 countries. ${ }^{29}$ Some firms were even unaware of some of their exposures were to Lehman subsidiaries (because of confusion over names of counterparties and of their relationship to Lehman Brothers). As a result they occasionally continued to make payments to bankrupt Lehman entities. Few firms could easily and immediately aggregate their Lehman exposures, in large part because of the barriers to automated processing already described in this section.

The lesson from Lehman Brothers is clear. Credit and counter-party risk management seemed to benefit very little with all the identifiers that were available, as they failed to address the simple but essential problem of "who belongs to whom". Without the understanding of corporate hierarchy, risk management methods (such as credit netting approach in counterparty risk management) cannot be applied efficiently. Standardized legal entity identification, together with an understanding of which corporate group each legal entity belongs to, would have helped firms obtain much more rapidly a broad understanding of their exposure to the Lehman Brothers failure and taken more rapid action to limit this exposure.

As discussed above, Lehman Brothers was far from being the first or only occasion on which the major global financial institutions faced difficulties in measuring their counterparty exposure to a failed entity. Several of our interviewees mentioned the substantial efforts to build internal systems of legal entity identifiers within their firms, dating back to these earlier episodes. ${ }^{30}$ These systems already give them a broad understanding of their counterparty exposures but they are stretched when it comes to dealing with the practicalities of actual default. The global LEI system is widely welcomed as a mean for all firms to obtaining the best possible quality of information on their counterparties, so they can deal somewhat more easily with counterparty default. Currently, global LEI system requests the LEI registrants to provide information on their direct and ultimate parents, and proactively requesting LOUs to collect information on the parent companies. The provision of this information should allow improvement in credit and counterparty risk management in the private sector.

A second area of application, mentioned by some interviewees, is improved measurement and management of counterparty risk in derivative trading and of credit risk in their bond and traded corporate loan portfolios. Here our findings must be qualified because none of those we interviewed are directly involved in credit or counterparty risk management. Many firms have for some time used statistical models for the analysis of credit portfolio risk for some time. By the early 2000s all large firms were applying tools such as KMV portfolio manager that allow calculation of both marginal and portfolio level default risk. Models of this kind provide the foundation for the advanced IRB methods for calculating capital for corporate credit exposures as part of the 2004 Basel II accord.

Subsequently a range of further quantitative models have been developed for the measurement of counterparty risk in OTC derivative markets (for a review of these methods see (Gregory, 2012)).

\footnotetext{
29 Source: (PWC, 2009). Page 6 summarizes the wide range of Lehman credit and counterparty exposures.

30 Internal systems for management of client reference data were already fairly well advanced in the early-2000s. (Grody et al., 2007) refer to a 2002 A-Team/ Reuter's study that found that $65 \%$ of firms had their own central reference data system.
} 
Management information and accounting standards require an adjustment of mark-to-market valuations of OTC derivatives, to take account of potential counterparty default. The industry now applies quite sophisticated modelling tools to capture the potential exposure at default and the correlation between these exposure and the probability of default occurring (so called 'wrong way risk' which arises when default is positive correlated with the valuation of exposures at default). Major firms have counterparty valuation adjustment desks to manage this credit valuation exposure, either through internal insurance (typically charging trading desks for their exposure to CVA) or by hedging through purchase of credit default swap protection. Since the crisis international regulatory rules now also impose additional capital charges for CVA.

Some of interviewees also referred to the use of the LEI to improve the risk assessment of some structured credit products, such as collateralized loan obligations. Standardized referencing will make it much easier to analyze underlying risk exposures, especially in portfolios containing many different structures.

Our interviews with data professionals suggest that the major firms believe they already have workable systems for identifying their major credit and derivative counterparties. These systems are not perfect, in particular as noted above they are not sufficiently quick or accurate for dealing with a default in real-time. They are though sufficiently credible to be used for the portfolio credit and CVA calculations, which firms have been conducting on a routine basis for some years.

There are potential benefits in terms of improved credit and counterparty risk-management from the creation of the global LEI. Once fully embedded in business processes, it will help provide senior management with more accurate and reliable summary of credit and counterparty exposures at a global level. For example (this is something we came across from separate sources, not in our interviews) this may helped firms deal better with the substantial difficulties they faced in monitoring credit and counterparty risk in periphery Europe.

Still, the overall impression from our interviews is that the firms themselves believe they already have generally good enough information on their exposures to both financial and non-financial corporates, and their relevant corporate hierarchies, in order to reach a sensible assessment of their own counterparty and credit risk exposures. The LEI will help in specific aspects of risk management (dealing with counterparty default, analyzing some structured credit exposures); and provide a valuable support to their own models of corporate hierarchies. But there was nothing from our interviews to suggest that the resulting private benefits to firms, in terms of reduced costs or higher revenues are anything like as large as the cost reductions from improved operational efficiency.

\section{Magnitude of benefits and barriers to adoption}

This section discusses the magnitude of benefits available from the creation of the LEI and the barriers to its adoption. This discussion is based mainly on secondary sources, relying to only a limited extent on our semi-structured interviews because these were largely restricted to qualitative rather than quantitative responses.

We also consider more briefly the additional benefits that may be obtained in combination with much more widespread standardization of communications and data recording across the entire financial services industry (where we suggest an order of magnitude figure for private benefits of $0.5 \%$ of global GDP). Finally (drawing in part on our interviews) we consider if perceived private benefits are at present sufficient to ensure universal adoption or whether further steps by policy makers need also be taken.

We are able to use our interviews to discuss the relative magnitude of private and social benefits. One reason this matters is that, while the social benefits are important they are not central to the decision of individual firms on whether or not to acquire an LEI; or to use the LEI in any particular business context. This decision will be made either because doing so offers them a bottom line return, through lower costs or higher revenues, or because of a direct regulatory instruction to acquire or use the LEI. 
Cost reductions are the most powerful reason for adoption. Regulatory compulsion is a comparatively crude instrument and cannot guarantee, for example, that the LEI reference data is accurate or that the number is used consistently in different firms or by different systems within a firm. The authorities want to see widespread adoption of the LEI on a consistent basis across the industry with good quality supporting data. Achieving this goal depends on the LEI offering sufficient private benefits to ensure every firm - both financial institutions and their customers - will voluntarily 'climb on board'.

One comparison that helps make this point is with the adoption of the global GS1 standards for product, location and shipment identification in the global supply chain. Individual firms have a strong private incentive to adopt and use these standards because without them they cannot participate in global supply as either a supplier or customer. Regulatory compulsion is not needed to make the system work. LEI must offer similar benefits to wholesale financial market participants.

\subsection{Quantification of benefits}

We did not try to quantify the scale of benefits from the introduction of the global LEI in our interviews. We do however discuss the likely range of potential benefits by reviewing publically available evidence on the various expenditures of major firms. In this exercise we refer extensively to (Grody et al., 2007), who provide the most detailed available discussion of cost savings from improved reference data, on both legal entities and financial instruments. ${ }^{31}$

We reach the following conclusions.

- $\quad$ To an 'order of magnitude' there are more than $\$ 1 \mathrm{bn}$ per annum of potential operational cost savings from the establishment of the global LEI in wholesale financial markets. By 'order of magnitude' we mean that the savings are certainly over $\$ 1$ bn and could be considerably higher.

- $\quad$ Further indirect private benefits can be expected, especially as more efficient processing allows the industry to extend is services to a wider range of customers, especially in emerging markets

- Extension of the LEI, making a universals standard not just in wholesale financial market transaction but also in corporate banking and trade finance could yield further private benefits

- There is also a bigger picture. Legal entity identification addresses only entity identification, one specific aspect of financial services operations. The potential gains from the standardization of all aspects of financial services are very much larger than from the LEI alone.

Our judgement of in excess of $\$ 1 \mathrm{bn}$ per year is based on the following argument. ${ }^{32}$ We can distinguish three specific areas where the availability of LEIs offer direct cost savings:

- Expenditure on external data. Inside Market Data Reference, Market Size and Share Analysis, 2006 Edition (reported in Grody et al., 2007) found that the total external spend on of data and information in the industry was \$13.6bn in 2004 (this figure was based on analysis of the revenues of the major vendors, amongst which Bloomberg, Reuters and Standard and Poor's together had a market share of 53\%); An updated analysis would result in a higher figure, in part because of the great increase in security market activities in emerging markets where data is relatively weak. One part of this expenditure is on entity reference data which would be considerably cheaper with a universal standard.

- Internal data management costs. To this external expenditure on reference data and other information must be added internal costs of data management, with all the major firms having to devote substantial headcount to acquiring and maintaining consistent information on customers and counterparties, for KYC and AML and for trade execution and processing. We

\footnotetext{
31 (Grody et al., 2007) summarize (see in particular their Figure 5, page 27) a number of industry reports into various aspects of operating costs, conducted in the early 2000's.

32 (Global LEI Foundation \& McKinsey and Company, 2017) suggests lower figure of around \$150 million per year, This is based on their survey based estimate (pg 16)) that around one-third of global capital markets industry operating costs of $\$ 5 \mathrm{bn}$ are spend on client on-boarding, client trade reconciliations trade allocations to clients and verification of client reference data, which in turn could be reduced by around $10 \%$ through widespread use of LEIs.
} 
believe (from our interviews and also from various industry reports) that the headcount in larger firms devoted to these activities is well in excess of 1,000 employees, across both the sell side and buy side institutions. We are not aware of any research that aggregates these costs, but they can be expected to average over $\$ 100 \mathrm{mn}$ per firm (if all-in costs per employee are $\$ 100,000$ ) and hence easily reach $\$ 5 \mathrm{bn}$ across the buy and sell sides of the industry. (Grody et al., 2007) (page 27) conduct some similar calculations, suggesting that these costs in the early 2000s could have amounted to as much as $\$ 12 \mathrm{bn}$ per year.

- Operational automation A third element of cost saving comes from reduction in trade fails and other operational failures i.e. the long pursued goal of 'straight through processing'. (Grody et al., 2007) quote a Tower Group (2006) report which estimated that in 2004 around $60 \%$ of trade failures were due to problems with reference data $(5.1 \%$ of trades that failed to settle was due to faulty reference data, $37 \%$ due to inaccurate or incomplete reference data and $20 \%$ due to disparities in referential data bases.) (Grody et al., 2007) also provide some quantification of costs referring to a variety of studies from the early 2000s, citing a SWIFT estimate that repairing trade fails cost the industry as much as $\$ 12 \mathrm{bn}$ per year. Additional costs also arise for asset managers as a result of faulty processing of corporate actions. Their own calculations on operational risk costs from trade and corporate action failures (Grody et al., 2007) Exhibit I, page 49, ) taking account of interest and other costs of delay of around $\$ 3 \mathrm{bn}$ in the largest 15 US firms.

Taking these three areas together it appears that direct cost saving from the global LEI, if adopted as the university entity identifier in global capital markets, can exceed $\$ 1 \mathrm{bn}$ per year. More detailed research is though needed to obtain a more accurate idea of these direct cost savings.

\subsection{Additional direct and indirect benefits}

There are many further private benefits, in addition to those from reduced expenditure on purchase of data, management of data and more automated processing. However these additional benefits are difficult to quantity. We can mention the following:

- Regulatory and other reporting The industry is facing new and more demanding requirements from regulators for 'granular' data broken down along several dimensions including counterparty, instrument, currency, jurisdiction and maturity.

Here there could be substantial cost savings. But achieving these savings is likely to require quite far reaching changes in internal data management systems and/or the requirements of regulators to ensure these are fully aligned across the industry. ${ }^{33}$ The LEI will only be one part of these changes.

- Development of new markets and services The adoption of a global LEI will make it easier for the major international firms to develop wholesale financial market services in emerging markets, avoiding the difficulties of creating their own internal identification systems for each jurisdiction from scratch. Over time this could considerably enhance their revenues

- Customer relationship management Considerable effort has been made, in many industries not just financial services, to develop effective systems for managing customer relationships, giving staff a full view of each customer rather than always seeing them through the lens of a single account. Such a complete view of the customer has potential to enhance revenues, by allowing firms to offer additional products, to more effectively price products and services based on the relationship as whole, and to offer a more effective and complete service. The LEI should, with additional further investment, help firms achieve more effective customer relationship management for their wholesale market clients.

- Extension to corporate banking. The LEI is being established for use in wholesale financial markets. But similar challenges of managing reference data apply in across the entire financial services industry. We can therefore see substantial further benefits from an eventual broadening of the scope of the LEI. The most obvious extension will be in corporate banking, so

\footnotetext{
33 See (Hille, 2013) for discussion of the changes being required for banks in Austria.
} 
it can be used in the full range of corporate financial services including term loans, cash management, lines of credit, syndicate lending, trade finance and project finance. ${ }^{34}$

The LEI is only one of many standardizations that could lead to substantial revenue and enhancement and cost savings in the industry. A report by Celent finds that total annual external spend on information technology systems by the entire financial services industry is around $\$ 175 \mathrm{bn}$ (Jegher, Lodge, \& Zhang, 2012) This is not just wholesale markets, a large part of this market is systems for retail banking and insurance. The Celent report for example includes all the expenditure on payments systems and customer interfaces. Still once all other elements of the costs of data and information management are taken account, including purchase of data, internal data management and dealing with exceptions, it can be seen that total data related spend across the entire financial services industry is substantial perhaps in the range of $\$ 500-\$ 1000 \mathrm{bn}$ per annum.

Our broad judgement is that full standardization of referencing, data management and messaging in wholesale and corporate banking could achieve cost savings in the region of $\$ 250 \mathrm{bn}$ per annum or $0.5 \%$ of global economic output. ${ }^{35}$ This is a guess, but not an implausible one, potential cost savings from adopting the most efficient arrangements for retail payments are known to be worth around $1 \%$ of GDP. ${ }^{36}$ A similar scale savings should be possible from the most efficient possible arrangements in wholesale markets. These numbers, moreover, are not the full story; they do not take account of additional 'dynamic' benefits resulting from allocation of savings to more efficient investment opportunities.

From this broad perspective the potential benefits of LEI are large indeed, but they rely on far more than simply entity identification and are likely to require substantial re-engineering of internal systems. Further discussion is beyond the scope of this paper.

\section{Barriers to adoption}

The final issue addressed by this paper is the barriers to widespread adoption of the global LEI. We asked in our interviews whether financial regulations are being developed in an appropriate way to support adoption. This question did not however elicit as much discussion as our other questions on the business and regulatory application of LEI and the practical challenges of implementation.

Therefore in this section we put forward our own views, in part informed by our interviews, but these are our own, not a consensus view of those we interviewed.

At a general conceptual level there is no disagreement. (FSB, 2012d), page 28-29, recognize that the LEI is a 'public good' i.e. something that can benefit many market participants and other stakeholders, not just those that pay for and organize the system. ${ }^{37}$ They argue that adoption is hindered by two factors, 'co-ordination failures' and 'network' externalities. ${ }^{38}$ This is a familiar challenge for all network industries, for example in mobile telecommunications. The private sector already has its own solutions for corporate identification. Whether the global LEI succeeds or fails in supplanting these existing solutions depends on whether or not it achieves critical mass in the full range of business applications.

\footnotetext{
34 (Global LEI Foundation \& McKinsey and Company, 2017) suggest savings from the LEI in trade finance could amount to $\$ 500 \mathrm{mn}$ per year across the industry.

35 See (Atkin, 2013) for an EDM Council perspective on what such full standardisation might mean.

36 See (Milne, 2006) for discussion of the theory and evidence relating to retail payments. The cost of retail payments ranges from around $0.5 \%$ of national income in the most efficient systems to around $2 \%$ in the lest efficient.

37 In more technical economics jargon, the LEI is 'non-rival', its use by one market participant does not limit its use by any other market participant.

38 There is an extensive research literature on both network goods (in which the benefits to one user depend on the number of other users of a good) and the economics of standards setting, highlighting such co-ordination failures and many possible various network externalities. See (Houstoun, Milne, \& Parboteeah, 2015) for a review.
} 
There is though a crucial role for regulatory adoption. As one of our interviewees aid regulation is critical to making the 'business case' for adoption of the LEI. Firms will do this if they are required to do so by regulators.

A related point that emerged from our interviews is the extent to which data and information have now become a priority concern for senior management of the major financial firms. The data managers we talked to typically have regular and direct contact at board level (something that was not the case a few years ago). Firms are increasingly aware of the strategic and technical challenges they face in getting value for money from the large expenditures they make on technology and information.

They are also all well aware of the challenge of working effectively with multiple internal systems, sometimes systems dating back to the 1970s and using old style programming languages such as COBOL. These complex internal arrangements, consisting of many 'siloed' systems that cannot easily be used together, is a legacy of many international acquisitions and of business initiatives. This though also poses a substantial challenge to the global LEI. To the extent that the adoption of the LEI requires re-engineering of internal systems, then it will be adopted only if there is a business case, with clear financial benefits or as a response to appropriately designed regulatory requirements.

Several interviewees raised concerns about validation and data quality. This issue is being addressed by both the ROC and the PSPG, together with the committee on evaluation and standards that will set quality standards for LOUs and for the issuance of LEIs. We can mention here a few salient points from our interviews.

- $\quad$ One view expressed to us that responsibility for application for LEI and for the validation of associated reference data should always lie with the registered firm itself. The concern here is that if a third party is applying for an LEI on behalf of someone else, then quality assurance is problematic. This issue has been discussed by the ROC and PSPG. The current approach is that third party registration will be possible with 'explicit permission' of the entity concerned, which will retain responsibility for data quality.

- It can be argued that a corporate group should be apply for LEIs in bulk for its own subsidiaries (for large corporate groups this will be the most efficient and in many cases only practical possibility for LEI applications, many subsidiaries have a legal rather than an operational existence and will not have capacity for making such applications themselves).

- Another issue is maintaining the integrity of the LEI numbering and associated reference data, following a corporate action such as a merger or takeover. This issue is being carefully addressed by both the ROC and the PSPG; an acceptable and cost-effective means of keeping reference data should be achievable.

To summarize, we identify a variety of technological, business, economic and regulatory barriers must be overcome if the LEI is to be universally adopted:

i) At the technological level firms must be persuaded that the LEI offers a more cost-effective identification solution, than existing identification solutions already incorporated into their existing systems.

The LEI must also offer better quality and lower cost entity identification than that available from existing sources. Therefore the immediate priorities in the LEI project, to maximize adoption, must be on keeping costs low and data quality high.

ii) If the perception is that the use of the global LEI is essentially a matter of regulatory compliance, and that it will be primarily used for regulatory reporting in a few markets e.g. OTC derivatives, then the business case for the widespread use of the LEI is relatively weak. This suggests a need for a commitment, as soon as practically feasible and at global level, to using the LEI in all aspects of regulatory compliance and reporting. Perhaps strongest criticism that we heard in our interviews, was the lack of clarity on what the system will be used for in the medium term, say three to four years from now. Firms understand what is required of them in the immediate future, but beyond this the development and application 
of the global LEI system remain unclear. This lack of clarity about the path ahead seems to us to be one of the biggest threats to the success of the global LEI.

In this respect we note what appears to us to be a regulatory 'own goal', with the US authorities developing a separate and independent global intermediary identifier number (GINN) for compliance with the 2010 FACTA regime. The purpose of the GINN is somewhat different from the LEI. It is supposed to be a branch rather than a legal entity identifier, in order to provide an audit trail for tracking down accounts of companies that may potentially owe tax to the US authorities. But branches are part of legal entities, it seems to us that cost savings for the industry and additional credibility for the global LEI could be attained by developing the GINN and the LEI on a consistent basis, combining branch and legal entity identification in single framework. ${ }^{39}$

A related concern raised by one interviewee was that the US requirement that all private firms providing goods and services to the Federal Government must have a Dun and Bradstreet number and that this poses an unnecessary barrier to adoption. It is certainly desirable that the global LEI should be allowed as an alternative identifier for this purpose. At an international level the global LEI could eventually be a universally accepted identifier for both tax purposes and for supply of goods and services to the public sector across the globe. Such an agreement would help establish the credibility for the LEI, although we are not persuaded that this is a critical barrier to adoption in financial services.

iii) The wider benefits of LEI, for example in data aggregation and risk reporting, require quite substantial accompanying investments in internal systems. The challenge here is that, while the potential cost savings from the global LEI and other data standards are clearly very large and can easily justify these investments, only a part of these benefits will come from LEI alone.

The attention now being paid to data issues by senior management in both industry and the regulatory authorities is very welcome; but to achieve the full scale of potential benefits this issue will have to remain at the top of their agenda for some years to come.

\section{Conclusions and policy recommendations}

This paper describes the global legal entity identifier (LEI) system, discusses the benefits obtainable from the new system and considers the barriers to its adoption. It draws on a series of semi-structured interviews undertaken in 2013 with data professionals on the design and operation of the new system.

The LEI offers two main types of benefit: the first is improving operational efficiency of basic operational processes, by removing unnecessary duplication and inconstancies in counterparty data and automating regulatory reporting; the second is providing better and more useable input data for understanding counterparty hierarchies and thus for aggregation of exposures and for monitoring and responding to systemic financial risk.

Our main finding is that the private benefits of the LEI system (i.e. the direct 'bottom line' benefits in terms of reduced costs or enhanced revenues) stem primarily from its application in basic operational processes. Drawing on existing research, we argue that value of direct measurable benefits of this kind, for firms in global capital markets, to be in excess of $\$ 1 \mathrm{bn}$ per year.

Some of our interviewees expressed quite strongly the benefits of the LEI for improving aggregation of exposures, risk management and the monitoring of systemic risk. We do not disagree, these are after all the main reason why the G20 governments are providing such strong support to the global LEI system. We however argue that these further benefits from having the LEI are primarily social not private, i.e. that the immediate bottom-line payoff from the LEI comes from its application in basic operational processes and it is this that will justify the investment by firms to using the LEI. Furthermore achieving these wider benefits depends on the universal adoption of the LEI in basic operations and this will be achieved only from perceived private benefits in reducing the costs of operations and regulatory reporting.

${ }^{39}$ For a related view see (Hygate, 2012) 
The following actions, in our judgement, therefore should be the immediate priorities for further development of the global LEI::

i) The development of a road map and timetable, setting out how the global LEI will move forward from its current relatively limited range of applications, to full use across the full range of capital market and corporate banking transactions.

ii) Discussion and agreements between regulators and industry on the use of LEI in regulatory reporting in all business areas, including equity, money market and bond trading, post-trade processing, corporate lending and cash management, foreign exchange trading, insurance exposures and all other contexts where the LEI could be used.

iii) Further guidance on the use of the LEI in KYC or AML regulation and in all aspects of prudential risk and tax reporting. In particular there needs to be clarification on the relationship between the LEI and the competing identifier, the GINN, introduced as part of the US FACTA tax regime on foreign companies.

iv) Detailed guidance on the use of LEI or other data standards in regulation of counterparty risk or in the development of recovery and resolution plans for systemically important institutions.

The efforts to create a safer financial system saw early agreement on the importance of better quality financial data, reflected in both the Dodd-Frank act and in European regulation and in the support for the global LEI given by the G20. The challenge now is maintaining this momentum, focusing on the full adoption of the LEI in the entire range of business processes, across all wholesale and corporate financial services and in all aspects of regulatory reporting. In this context most recent announcements by global regulators are encouraging (Buch, 2017; LEI ROC, 2018), suggesting some progress in the adoption of the LEI in a range of regulatory reporting beyond its original application to OTC derivatives trade reporting warehouses. These encouraging developments in regulatory adoption will though have to be pursued further, in order to reap the full private and social benefits of the LEI system. 


\section{Appendix: interview questions and interview summary}

\section{Conduct of the interviews}

In support of this research, we conducted structured twelve structured interviews using telephone or Skype, to elicit practitioner opinions about the global LEI system. The interviews were arranged on a confidential basis. We have agreed not to name the individuals we spoke to or to give any indication of the firms for whom they work.

Our interviewees were five senior data managers in the major global investment banks and seven industry experts working for advisory firms or consultancies (most of whom are active in the LEI PSPG). Interviews lasted between 30 minutes and 70 minutes and were organized around the following "initial questions":

- What are the major cost, efficiency and risk-reductions that could be achieved from using LEI?

- How important is it to have good hierarchy reference data as part of the LEI in order to achieve these benefits? Should this ownership hierarchy be provided by the LEI system?

- Current regulations (Dodd Frank in the US, European Market Infrastructure Regulation EMIR in Europe) are imposing quite challenging requirements on firm's OTC businesses. Can LEI be helpful to meeting these challenges and is it being developed in an appropriate way? Are other elements of the current re-regulation of global financial institutions being developed in a form consistent with the business adoption of LEI; or are other regulatory initiatives actually an impediment to adoption?

All the interviews developed as wide ranging conversation about the LEI initiative. The bullet points functioned as a check list to ensure that we had not forgotten to ask questions about the points of most importance to our research and to organize our subsequent write up.

We took extensive hand written notes of the interviews. The interview summaries and the first draft of the paper were circulated to all interviewees, to give them an opportunity to correct any misunderstandings or add further points they think are relevant.

\section{Summary of interviews}

The remainder of this appendix summarizes the comments made to us during these interviews. Here in this appendix we are 'unselective', including - to the best of our understanding - every point made to us by our interviewees (though this has required quite a lot of rewording to ensure that this summary is in coherent written English). The main text of our paper, in contrast, is interpretative; we select and restate those points from the interviews that are most relevant to the narrative of our paper.

Question 1: What are the major cost, efficiency and risk-reductions that could be achieved from using LEI?

\section{a. General perspectives}

One interviewee suggested that there are only four important elements to data management in financial services: identification of instrument, identification of entity, contractual details (i.e. the obligations being entered into and the role performed), and reconciliation of hierarchies (so you know who exactly you are dealing with). Automation of this information will yield a wide range of benefits both in terms of processing efficiency (both pre and post-trade) and in on-boarding of counterparties.

In financial industry, everything is about data; knowing the counterparty and the securities that are trading. If data can be collected electronically, then there is no data ambiguity. This can lead to substantial social benefits. This is one fundamental principle for the global LEI for going forward.

There is currently no common identifier between firms and within the firm for an individual legal entity. Where firms have used external identifiers these have the AVOX id or BIC, neither of which provide all the information that they need. What the industry need is a consistent identifier that can be cross-referenced and can be used to consolidate and aggregate positions, for example credit 
balances in risk management and counterparty exposures for derivative and commodity trading; and provides key information about location and activities. In short, a single thing to bring everything together.

A fundamental problem in the industry is that there is a lack of good quality underlying granular data. In some jurisdictions it is hard to obtaining identity information because there is public record; however, in other jurisdictions, lack of transparency makes it hard. LEI reduces the cost for creating transparency of data.

An interviewee mentioned that the benefits of LEI are across the entire range of business activities, allowing quick and accurate identification. Another interviewee said simply having a consistent unique identifier is already a huge benefit; this is particularly important for financial industry, due to the very complex differences across jurisdictions, across products, and across technology and information support.

One interviewee mentioned that another major issue for LEI implementation is the tremendous consolidation of the past (two) decades, with large firms having inherited a large number of legacy systems each with their own internal identifiers. Now that pace of acquisition had slowed there was an opportunity for consolidation and harmonization of these systems, and that LEI and other identification would play a key role in this task.

b. On-boarding and knowing your customer (KYC)

One benefit of LEI is the on-boarding of clients. Industries should have a single identifier to manage everything coming in, to join things together for a single ultimate parent which has thousands of entities below it. It certainly helps reduce duplicates in the client master file during on-boarding. Although some large investment banks have their own matching service utility which effectively looks at names of clients and languages, having a standard global LEI can still make things a lot easier. One example is that client establishes a relationship in the US and then in the UK one year apart; without a global identifier these may not necessarily be linked up at all. Another example that we were given is the different names of counterparties. More than one interview mentioned the problems with 'Lehman Brothers' which had several identifications in firm's internal systems at the time of its failure in the autumn of 2008; other examples of name confusion mentioned include Long Term Capital Management and several currently operating firms.

There are two types of costs for on boarding: direct external costs which are the fees that a firm pays for the data services used to identify the clients; internal costs which are the costs from the IT operational support needed to manage and maintain this information and once they are acquired. A unique LEI should simplify everything and reduces these costs.

Although a number of identifiers are available from data vendors (Dun and Bradstreet, Thomson Reuters and Bloomberg), they cannot be used as an automatic tool for identification purpose because there is no cross reference information between these identifiers.

For the KYC aspect, there has been a collective action problem, a failure to collect and validate information once and once only for each client. As a result the firms sometimes know little about who they are doing business with or must spend unnecessarily on obtaining reliable data. LEI will provide more control, more validity and more accuracy and transparency about each entity a firm is dealing with; a firm only needs one review for each client, instead of a number of reviews for the same client due to the multiplicity of client identifications.

There is also a major problem of keeping data up to date. An example is about a client having multiple accounts; when there is a change such as an acquisition, LEI can help to ensure that this change is reflected in internal data much more efficiently with less operational risk. Third-party registration has caused a lot of quality issue in the past; for example, data of entities without being certified can lead to fake or made-up entities.

c. Anti-money laundering(AML)

Closely related to KYC is the challenge of complying with AML regulations. Several interviewees mentioned the large recent fines imposed by the US authorities. There is a new emphasis on legal compliance and hence on data. 
Another interviewee described the importance of an AML "checklist" it is essential to demonstrate that you have complied with every specific requirement of the regulations and automation of processes, facilitated by accurate and reliable legal entity identification, is the way to do this. As with KYC a major headache in AML is ensuring data is fully up to date.

\section{d. Buyside efficiencies}

Buyside firms also benefits from greater efficiency in KYC and AML processing. But there are further benefits. Major asset managers, for example PIMCO, have thousands of funds which are unallocated before a trade, but which are credited with cash or securities after a trade. The LEI will greatly facilitate these allocations.

Another benefit about KYC is that LEI can help certain entities such as trusts to avoid investing in the entities that are associated with controversial business areas, such as tobacco and arms trade.

One interview mentioned that underwritten securities require manual interventions to ensure they are credited correctly to the client accounts.

e. Data aggregation

LEI can make the work of data aggregation a lot easier and cost efficient. There are many problems in firms that are related to data aggregation.

One example is evaluating counterparty exposures to implement credit limit in the complicated index securities including CLOs. A typical CLO has as many as 200 underlying names, and a large investment bank can have around 200 CLOs on the book. There are different names of the same entity in those CLOs, and it is difficult to identify the same counterparties. The cost for paying outside vendor to identify which are the common counterparties is massive.

Another example given by an investment bank is that it has 6-7 systems for trading swaps, and it is very difficult for the systems to communicate with each other due to the lack of a unique identifier. Again aggregation is very challenging without a single common identifier.

f. Regulatory reporting

There is a need for the efficiency in regulatory reporting, especially with the increasing burden of reporting requirements. LEI can help to reduce cost for this reporting. This is not just a banking issue, for example in the US, the insurance regulators are planning to require insurance companies to tag all of their holding in their companies with LEI for reporting.

It is recommended by several of our interviewees that regulators should require LEI to be tagged for all types of financial products. This also means that the firms that issue securities or negotiate bank loans or other tailored financial products should have their own LEIs.

g. Trade and post-trade processing

Some of independent data professionals and data managers mentioned the reduction in trade failures and the promotion of straight through processing as a further major cost reduction. The data managers we interviewed from the major firms only mentioned the automation of trade-execution and post-trade processing in passing, although this may reflect the fact that the main responsibilities for these operations lies elsewhere in the firm.

There were different opinions on the application of LEI in automated computer and high-frequency trading. The post-trade process of matching and confirmation can be substantially shortened when there is standard identification and automation. However, it is also suggested that for the time being, LEI should mainly help the back office processing and front office on-boarding mechanism, not for the actual trade. This is because it is computationally costly to include a 20-digit LEI in a high-frequency trading environment.

h. Managing and monitoring counterparty and credit risks.

One interviewee drew a distinction between the operational and risk management benefits of LEI (a distinction we have used in our main text). The main risk management benefit mentioned to use was dealing with counterparty default. Several interviews referred the experience with Lehman Brothers. With LEI firms will be able to move quickly to identify the counterparty and to stop payment/transaction to counterparties that failed. A number - especially those working outside of the major firms - spoke with some passion about the benefits of better risk management, on for 
example suggesting that if the benefits of better client on-boarding and KYC were worth one 'util' then the wider risk management benefits were worth twenty 'utils'.

Despite this emphasis on risk-management benefits, the discussion of risk management was all at a general level, mentioning better risk information or regulatory reporting. Our interviews few specific examples of cost or efficiency benefits in risk-management from using the LEI. We recognize thought that this may be because none of our interviewees were risk-management professionals, who might suggest other specific examples.

Question 2: How important is it to have good hierarchy reference data as part of the LEI in order to achieve these benefits? Should this ownership hierarchy be provided by the LEI system?

The interviewees provided a wide range of opinions to this question. Most interviewees from investment banks said that they have their own system for building up counterparty hierarchy; so hierarchy is not a central issue to them. What they need to do is to attach the LEI to the existing hierarchy system. They said that they understand the corporate structure of the clients that they are dealing with. Other vendors such as Thomson Reuters and Bloomberg also provide hierarchies. The ones who don't have good understanding of corporate hierarchies are the regulators, and the regulators should ask the industry how to construct hierarchies, not imposing solutions on the industry.

Most interviewees think that the aim of LEI is not the provision of hierarchy structure. This is because LEI is a static identifier, but ownership can change anytime. The focus of LEI should be on keeping core information fully updated, including industry classification code, corporate status (profit v. non-profit); country of residence (which may differ from legal jurisdiction).

A service provider (which can be a utility behind LEI but could be a third party) should provide the hierarchy information instead of the core LEI. Core LEI should contain things that don't change, e.g. industry classification code, country code. Also, there is no consensus about ultimate parent (ultimate majority legal owner) and related issues; in practice four different categories are considered: controls (include golden shares); legal ownership; beneficial ownership; beneficial Interests; there is no consensus for how which to be considered and how the hierarchy can be done now.

One interview suggested strongly that hierarchy should not be done in LEI at all; all LEI should do is to provide a reference number, and this is enough. Entities should provide hierarchy data on who owns them by self-reporting. Another interviewee suggested that the information for (a) who controls it and (b) what does it control are already enough. Other information should be separated.

There are also strong views, however, supporting hierarchy as an important component of LEI, especially from independent data professionals. One interviewee said hierarchy transparency is one of the big promises from LEI; hierarchy data is currently incomplete and in very questionable quality, and firms must get this data from data vendors or do it themselves. Ability to get a single view of hierarchy data from LEI will reduce cost significantly for everybody. It is critical to have reference hierarchy data as complete as possible. Although there are gaps in the hierarchy which global LEI system may not be able to capture (mainly due to the firms hiding their own corporate structure from the public), the global initiative should try to narrow those gaps. The global LEI system should reveal firms which try to hide their hierarchy structure to the data users, and let the users judge themselves whether to deal with those firms or not. However, the interviewee also said that hierarchy does not necessary have to be part of the core LEI at the initial stage if this slows things down.

Another interviewee said whether hierarchy should be part of the second stage of LEI is an open question. It is hard to evaluate whether the extra amount of effort required to achieve the hierarchy structure within global LEI system is worthwhile. Particularly, it is very difficult for a LOU to maintain a consolidate picture of a multinational firms, although there are possible solutions like the exchange of information between LOUs or COU taking the job to consolidate multi-national firms. However, it should also be aware that hierarchy is not the initiative of the COU and the LOUs. So, it is unclear whether global LEI system should provide hierarchy information. 
Another interviewee argued that only having one group of people with access to the data and want to make money from the hierarchy is incredibly dangerous, because inevitably the way they do it is by following herd. Everyone is going off the cliff at the same time. It is important to have the core principle lay down by the ROC and by the regulation that are accepted by all players, before anyone would become an established player.

One other suggestions was that LEI will be useful to them in maintaining their understanding of counterparty and client hierarchies, by the provision of verifiable objective information; they will welcome LEI as a source of information on percentage of shareholding, especially what entities have majority shareholdings. These are objective fact that can be checked, not subject to judgement. They can use this as an input to their own hierarchy analysis. But the final development of understanding of hierarchies inevitably involves applying judgements and this judgement should be internal decision within the firm, not imposed by LEI

Question 3a: Current regulations (Dodd Frank in the US, European Market Infrastructure Regulation EMIR in Europe) are imposing quite challenging requirements on firm's OTC businesses. Can LEI be helpful to meeting these challenges and is it being developed in an appropriate way?

One interviewee said LEI is a tremendous enabler for the current regulations. Therefore, the OFR should try to streamline regulatory reporting in the US with LEI, and should go further than OTC counterparty trading. Another interviewee also suggested a similar point and said no transactions should be done without a LEI or pre-LEI.

However, it has also been pointed out that although LEI itself has huge potential to a global solution, and push more firms to use LEI. Some jurisdictions may not like the LEI because of the dominant role of the US and the Europe, and this has to be resolved. But as more and more jurisdictions are following the standards, this eventually should not be a problem.

A number of interviewees said regulators should adopt LEI for regulatory reporting on a global basis. In Europe, although LEI is used in EMIR, the adoption of other identifiers at the same time is a major failing in EMIR. There is also similar concern for the adoption of Dun and Bradstreet number in the US. At this moment, the situation is that only the US and Europe use LEI for transaction of certain products. Japan is quite keen to see the system to be a success, but they do not want to have the system solely run and governed by the US industry.

Question 3b: Are other elements of the current re-regulation of global financial institutions being developed in a form consistent with the business adoption of LEI; or are other regulatory initiatives actually an impediment to adoption?

One interview suggested that current regulation needs to be a lot clearer, and regulatory should use reference data to classify financial/non-financial counterparties. There is a huge gray area under different regulation (Dodd-Frank and EMIR classifications are not entirely consistent). And there should be much more sharing of information across border.

There is not enough clarity about use of LEI for regulatory purposes, except for OTC derivative trading. A much more desirable situation is that any place that the regulators require data that needs identification of counterparty should be using LEI (including security reporting and issuance in security markets).

Another interviewee said the re-regulation has not been developed with the adoption of LEI in mind because of the delay of LEI system. There is a degree of fragmentation in the pre-LEI world, with slightly different approaches taken by different LOU, and this may not be easy to overcome later. Similarly, core principles of LEI should be the same everywhere, although some local variation may exist. Countries that do not follow these standards should not have their LOUs recognized. Suggested countries that might be taking a somewhat inconsistent approach included Russia, Japan, and UK (but we did not pursue the question in this interview of how exactly their LEI issuance might differ).

Historically, too much regulatory work being done in the US and the Europe was undertaken independent of each other historically. But the situation has been improved recently, and a lot more 
coordination is happening now. More cooperation, more team work and more discussion between regional regulators should be encouraged.

From the industry perspective, there is a lot of confusion: what is the time-frame, what is ROC doing, the existence of different initiatives within US and around the world; all have not been communicated to the industry. The industry does not know what to do. The largest firms may be in a better position but medium-sized and smaller firms don't understand the ROC and the global initiatives. The industry generally doesn't fully understand the benefits of LEI. From the industry point of view, a lot of firms in the industry think what the ROC has done in the last 6 months is not really important to their business activities (the interviewee who said this emphasizes that this was not their own view, they thought considerable progress had been made, but that this was the perspective of many in the industry.)

Another comment is that there are substantial challenges with the US Y14 data collection that supports the regular assessment and stress testing requirements required under Dodd-Frank ${ }^{40}$ and FSA liquidity reporting in the UK. These exercises have caused enormous difficulties in practice.

Other Issues Raised by the Interviewees

We complete our interview summary by noting a number of further issues that emerged in the course of our interviews, mainly about data quality and data governance.

An interviewee pointed out a key potential problem with entity identification LEI is about country identification. A company registered in Cayman Islands but operating in the US could be considered a US company, but it will be under Cayman Islands under LEI. This has to be considered when LEI is issued. One possible suggested solution is to include both country of registration and country location where the decision makers are found.

There was also discussion about the role of senior management - board members and chief executive officer. In the past they have not engaged in data issues in detail. The command has always been just find a solution and they have not been reluctant to make investment in data solutions. This raises the question of whether they will be willing to spend money on the adaption operational systems to take advantage of the full scope for efficiency gains from LEI.

A number of interviewees said there is now a fundamental change in attitudes. On-boarding correctly and streamlining of data processes can result in significant cost savings. CEOs are realizing how important this is. They are asking the question "is data represented at this meeting". Another interviewee commented that 10-12 years ago the focus was entirely on product transactions, with nothing on clients, settlement instructions or credit controls. This has all changed with the Chief Data Officer playing the central role and meeting monthly with the CEO.

Another said the firms that have been reluctant to standardize their internal data/models to allow for the identification of the same entities, they are hurting themselves even without LEI. Although LEI is now only another Reuters or Bloomberg identifier, it will become larger; firms that were reluctant will wake up and invest in their systems which adopt LEI. Another interviewee commented that firms will need to recognize the benefits of LEI, not just for the regulatory mandate. The situation should be, at some point, if you don't have an LEI you will be reputationally disadvantaged. So, it is better to get an LEI in order to be part of the global financial network.

Data quality and validation was also discussed by several interviewees. LEI provides transparency and information for updating knowledge in certain contexts, detecting corporate events and updating any change in corporate structure. A major challenge though is the different requirements on disclosure in different jurisdictions, with banks often signing non-disclosure agreements about basic customer information. A number of jurisdictions were mentioned which have very limited disclosure requirements on e.g. ownership or financial transactions, but this is a headache because it limits the ability to aggregate information even with an LEI.

40 For a short description of these data requirements see

http://www.clevelandfed.org/Banking/Financial_Reporting_and_Data/lcb2012/FRY-14.pptx 
One interviewee said although LOUs are responsible for maintaining the data and data quality, they should not be turned into research organization and be given the burden to validate everything. A commonly held view is it is the job of the entity to make sure the data is correct (as demanded by regulators and jurisdictions), not the responsibility of the registries. In the example of the GS1, if firms do not have the correct information, they don't get orders, so the firms make sure their information is correct. If LEI is only used for regulatory reporting, the entities are not going to have the same type of willingness to maintain correct information. If LEI is used widely for financial transactions, this will drive the accuracy of LEI. Regulatory requirement should just be a beginning, and should not be used for the long-run for maintaining data quality.

One interviewee suggested that senior managers should be involved to ensure the data quality of LEI, and granularity must be taken to the lowest level. Third-party registration has caused a lot of problems with data quality in the past; for example, data of entities without being certified can lead to fake or made-up entities. Some third party system suppliers also do vertical sale to all the silos to boost the revenues.

A related issue about third party vendors is that they have taken advantage of the major firms, by selling separate services into all the different vertical silos. They have been more interested in boosting their own revenues than in providing the most cost-effective solutions at cross-business line and cross-jurisdictional level. A move to integrated data management at firm level should provide an opportunity to bargain for much better terms from the vendor.

Finally one interviewee raised the issue of the structure and governance of the LEI system itself. They mentioned that if it is to work LEI needs to be a truly federated system, able to understand local language and local industry. There were failures of other business entity identifiers before; LEI can fail if it is not done properly in every locality.

\section{References}

A-Team_Group. (2009). Business Entity Identifiers: The Crucial Foundation for Accurate Risk Management. Retrieved from http://finetik.files.wordpress.com/2009/05/business_entity_identifiers_wp_a-team_mar09.pdf

Alexander, L. (2010). Statement on Legal Entity Identification for Financial Contracts. Federal Register, 75(229), 74146-74148.

Alexander, L., Das, S. R., Ives, Z., Jagadish, H. V, \& Monteleoni, C. (2017). Research Challenges in Financial Data Modeling and Analysis. Big Data, 5(3), 177-188.

Atkin, M. (2013). EDM Broadcasts: Identifying the actions affecting data management and the implications for financial institutions and their suppliers. Retrieved from http://www.edmcouncil.org/broadcasts

Bailey, A., King, M., \& Tucker, P. (2011). Uncorrected Oral Evidence Taken before the Joint Committee on the Draft
Financial
Services
Bill.
London:
Hansard.
Retrieved from

http://www.parliament.uk/documents/joint-committees/Draft-Financial-Services-Bill/Ucjcdfsb031111ev1 1.pdf

Bottega, J. A., \& Powell, L. F. (2011). Creating a linchpin for financial data: Toward a universal legal entity identifier (Finance and Economics Discussion Series No. 2011-07). Journal of Economics and Business (Vol. 64). https://doi.org/10.1016/j.jeconbus.2011.06.002

Braswell, J., Lannom, L., Milne, A., Jim, N., Paskin, N., \& Traub, K. (2012). Response to the Financial Stability Board's Request for an Engineering Study on the Best Approach to Managing the Structure and Issuance of Legal Entity Identifiers (LEIs). Retrieved from http://papers.ssrn.com/sol3/papers.cfm?abstract_id=2197269

Buch, C. (2017). Data needs and statistics compilation for macroprudential analysis. In keynote remarks at the Irving Fisher Committee-National Bank of Belgium Workshop.

Carmassi, J., \& Herring, R. (2016). The corporate complexity of global systemically important banks. Journal of 
Financial Services Research, 49(2-3), 175-201.

Chan, K. K., \& Milne, A. (2013). The Global Legal Entity Identifier System: Will It Deliver? (Economics Working Papers). Retrieved from https://papers.ssrn.com/sol3/papers.cfm?abstract_id=2325889

Draghi, M. (2009). Re-establishment of the FSF as the Financial Stability Board. Retrieved from http://www.fsb.org/wp-content/uploads/r_090402.pdf

Fan, L., \& Flood, M. D. (2018). An Ontology of Ownership and Control Relations for Bank Holding Companies. In Proceedings of the Fourth International Workshop on Data Science for Macro-Modeling with Financial and Economic Datasets (p. 3). ACM.

Flood, M. D., Jagadish, H. V, \& Raschid, L. (2016). Big data challenges and opportunities in financial stability monitoring. Banque de France, Financial Stability Review, 20.

FSB. (2009). Financial Stability Forum re-established as the Financial Stability Board. Basel. Retrieved from http://www.fsb.org/2009/04/financial-stability-forum-re-established-as-the-financial-stability-board/

FSB. (2012a). A Global Legal Entity Identifier for Financial Markets. Retrieved from http://www.financialstabilityboard.org/publications/r_120608.pdf

FSB. (2012b). Charater of the Regulatory Oversight Committee for the Global Legal Entity Identifier (LEI) System. Retrieved from http://www.financialstabilityboard.org/publications/r_121105c.pdf

FSB. (2012c). Formation and launch of FSB Legal Entity Identifier (LEI) Private Sector Preparatory Group (PSPG). Retrieved from http://www.financialstabilityboard.org/publications/r_120803.pdf

FSB. (2012d). Fourth progress note on the Global LEI Initiative. Retrieved from http://www.financialstabilityboard.org/publications/r_121211.pdf

FSB. (2013). Fifth progress note on the Global LEI Initiative. Retrieved from http://www.financialstabilityboard.org/publications/r_130111a.pdf

FSB. (2017). Governance arrangements for the unique transaction identifier (UTI): Conclusions and implementation plan. Basel. Retrieved from http://www.fsb.org/2017/12/governance-arrangements-for-the-unique-transaction-identifier-uti-conclusi ons-and-implementation-plan/

FSB. (2018). Governance arrangements for the unique product identifier (UPI) - Second Consultation Document. Basel. Retrieved from http://www.fsb.org/2018/04/governance-arrangements-for-the-unique-product-identifier-upi-second-con sultation-document/

FSOC. (2012). 2012 Annual Report. Retrieved from http://www.treasury.gov/initiatives/fsoc/Documents/2012

Global LEI Foundation, \& McKinsey and Company. (2017). The Legal Entity Identifier: The Value of the Unique Counterparty ID. Retrieved from https://www.mckinsey.com/ /media/McKinsey/Industries/Financial Services/Our Insights/The legal entity identifier The value of the unique counterparty ID/Legal-Entity-Identifier-McKinsey-GLEIF-2017.ashx

Gregory, J. (2012). Counterparty Credit Risk and Credit Value Adjustment: A Continuing Challenge for Global Financial Markets (The Wiley Finance Series) (2nd ed.). John Wiley \& Sons. Retrieved from http://www.amazon.co.uk/Counterparty-Credit-Risk-Value-Adjustment/dp/1118316673

Grody, A. D. (2018). Can a globally endorsed business identity code be the answer to risk data aggregation? Journal of Risk Management in Financial Institutions, 11(4), 308-327.

Grody, A. D., Harmantzis, F., \& Kaple, G. J. (2007). Operational Risk and Reference Data: Exploring Costs, Capital Requirements and Risk Mitigation (SSRN). Journal of Operational Risk (Vol. 1). Retrieved from http://papers.ssrn.com/sol3/papers.cfm?abstract_id=849224 
Harrell, M. C., \& Bradley, M. A. (2009). Data collection methods. Semi-structured interviews and focus groups. Rand National Defense Research Inst santa monica ca.

Hille, E. (2013). Recent developments in restructuring the Austrian banking reporting system. Journal of Banking Regulation. https://doi.org/10.1057/jbr.2013.12

Houstoun, K., Milne, A., \& Parboteeah, P. (2015). Preliminary Report on Standards in Global Financial Markets.

Hygate, J. (2012). When Your Number's Up... $\quad$ Retrieved from http://www.fostermoore.com/tag/entity-numbers/

Jegher, J., Lodge, G., \& Zhang, H. (2012). IT Spending in Banking: A Global Prespective.

Jenner, B., Flick, U., von Kardoff, E., \& Steinke, I. (2004). A companion to qualitative research. Sage.

LEI ROC. (2013). LEI Regulatory Oversight Committee (ROC): 1st progress note on the Global LEI Initiative. Retrieved from http://www.leiroc.org/publications/gls/roc_20130308.pdf

LEI ROC. (2015). The Global LEI System and regulatory uses of the LEI: progress report. Retrieved from https://www.leiroc.org/publications/gls/lou_20151105-1.pdf

LEI ROC. (2016). Collecting data on direct and ultimate parents of legal entities in the Global LEI System-Phase 1. Basel. Retrieved from https://www.leiroc.org/publications/gls/lou_20161003-1.pdf

LEI ROC. (2018). The Global LEI System and regulatory uses of the LEI: progress report. Retrieved from https://www.leiroc.org/publications/gls/roc_20180502-1.pdf

Milne, A. (2006). What is in it for us? Network effects and bank payment innovation. Journal of Banking $\mathcal{E}$ Finance, 30(6), 1613-1630. Retrieved from http://ideas.repec.org/a/eee/jbfina/v30y2006i6p1613-1630.html

Piechocki, M. (2017). Overview of international experiences with data standards and identifiers applicable for big data analysis. IFC Bulletins Chapters, 44.

Powell, L. F. (2011). Legal Entity Identifier: What Does it Mean to You? Retrieved from http://www.docstoc.com/docs/159491506/office-of-financial-research

PWC. (2009). Lehman Brothers' Bankruptcy: Lessons learned for the survivors. Retrieved from https://www.pwc.com/jg/en/events/lessons-learned-for-the-survivors.pdf

ROC. (2013). LEI Regulatory Oversight Committee Makes Progress in the Establishment of the Global LEI System and Produces Key Decision for Interim Global System. Retrieved from http://www.leiroc.org/publications/gls/roc_20130619.pdf 